\title{
Thrombin generation - a potentially useful biomarker of thrombotic risk in Philadelphia-negative myeloproliferative neoplasms
}

\author{
Romeo-Gabriel Mihaila
}

The diagnosis of essential thrombocythemia and polycythemia vera is often made during a thrombotic event which can be serious. Philadelphia-negative chronic myeloproliferative neoplasia patients have an increased thrombotic risk. This is assessed using various scoring systems but these are far from ideal and individual risk. The currend trend to personalised medicine requires finding the most useful thrombotic risk biomarker in these patients. Routine tests for coagulation do not take account of both pro- and anti-coagulant factors which is why these tests are not useful in patients with Philadelphia-negative myeloproliferative neoplasms. Thrombin generation reflects more accurately the balance between pro- and anti-coagulant factors. Some parameters of thrombin generation such as the endogenous thrombin potential are higher in Philadelphia-negative myeloproliferative neoplasm patients, especially in JAK2 V617F carriers than in healthy controls. They are even higher in those with reactive thrombocytosis. The JAK2 V617F allele burden correlates more with a higher thrombin generation potential in patients who are not treated with hydroxycarbamidum. Instead, JAK2 V617F-positive patients with Philadelphia-negative myeloproliferative neoplasms were the most sensitive to hydroxycarbamidum, as was reflected in lower values of platelet thrombin generation potential. The use of thrombin generation examination in these patients would enable detection of imminent thrombosis and personalised prophylactic management.

Key words: essential thrombocythemia, JAK2 V617F, myeloproliferative neoplasms, personalized medicine, platelets, polycythemia vera, thrombin generation, thrombotic risk.

Received: June 26, 2016; Accepted with revision: December 15, 2016; Available online: January 6, 2017 https://doi.org/10.5507/bp.2016.064

Faculty of Medicine, "Lucian Blaga" University of Sibiu and Department of Hematology, Emergency County Clinical Hospital Sibiu, Romania Corresponding author: Romeo Gabriel Mihaila, e-mail: romeomihaila@yahoo.com

\section{INTRODUCTION}

Cancer is a risk factor for thrombotic events. Black ethnicity and chemotherapy are also thrombotic risk factors for patients with cancer. Khorana et al developed a score to estimate the risk of venous thromboembolism in patients indicated for chemotherapy, which included the site of cancer, the platelet and white blood count before chemotherapy, the hemoglobin level or the use of erythropoietin, and the high body mass index ${ }^{1}$. This score was validated in many clinical trials. Unfortunately, only a small number of patients had hematologic malignancies in the group studied by Khorana et al. Multiple myeloma, non-Hodgkin and Hodgkin lymphoma had the highest risk for venous thromboembolism in patients with hematologic malignancies in a study on hospitalized cancer patients ${ }^{2}$. But patients with Philadelphia-negative myeloproliferative neoplasms (especially those with essential thrombocythemia or polycythemia vera) are rarely hospitalized. Essential thrombocythemia patients aged over 60 years, with white blood count over $11000 / \mathrm{mm}^{3}$, and thrombotic events in the history have higher thrombotic risk ${ }^{3}$. The presence of cardiovascular risk factors and the mutation $J A K 2 \mathrm{~V} 617 \mathrm{~F}$ are other risk factors included in an international prognostic score of thrombosis of these patients ${ }^{4}$. Patients with polycythemia vera have two main thrombotic risk factors: age over 60 years and thrombotic events in the medical history 5 . Additional risk factors are: diabetes mellitus, arterial hypertension, congestive heart failure, hypercholesterolemia, and smoking ${ }^{4}$. The presence of JAK2 V617F mutation in patients with myeloproliferative neoplasms increases the thrombotic risk (RR 2.94) compared to patients without this mutation; the risk is even higher in those who also have thrombophilia (especially in the presence of lupus anticoagulant and factor V Leiden) (ref. ${ }^{6}$ ).

But these risk factors are not ideal for thrombotic risk quantification in Philadelphia-negative myeloproliferative neoplasms patients. I decided to do a literature minireview on a potential useful biomarker: thrombin generation. I selected articles published in PubMed in the last 10 years, using the terms "thrombin generation", "essential thrombocythemia", "polycythemia vera".

\section{THE THROMBOTIC RISK OF PATIENTS \\ WITH PHILADELPHIA-NEGATIVE MYELOPROLIFERATIVE NEOPLASMS}

Patients with Philadelphia-negative myeloproliferative neoplasms (Ph-negative MPN) are likely to develop venous or arterial thrombosis. About two-thirds of all these complications are represented by transient ischemic attacks and stroke ${ }^{7}$. Those who are JAK2 V617-positive have higher risk of developing thrombotic complications ${ }^{8}$. A ce- 
rebral vein thrombotic event can be the first clinical manifestation of a Ph-negative MPN. The main thrombotic risk factors are: endothelial dysfunction, leukocytosis, vascular cell activation, high thrombin generation, decreased serum levels of protein $\mathrm{S}$, and elevated plasma viscosity. In addition, arterial thrombotic events appear more frequently in carriers of cardiovascular risk factors, while venous thrombotic events are more frequently encountered during oral contraceptive use, in pregnancy or puerperium ${ }^{7}$. The presence of $J A K 2 \mathrm{~V} 617 \mathrm{~F}$ mutation is associated with leukocytosis and changes in markers that explore blood clotting disorders ${ }^{9}$. A high white blood count is a new thrombotic risk factor, due to its neutrophilic component. There is growing evidence of its involvement, but polymorphonuclear neutrophils of $J A K 2$ V617F-positive patients with Ph-negative MPN have not been able to increase thrombin generation compared to healthy subjects in the study of Perrin $\mathrm{J}$ et al. ${ }^{10}$. However, the group of studied patients was not large. It would be desirable to continue the research in this field. The prophylaxis with antiplatelet drugs is indicated in subjects with arterial thrombosis risk (if the platelet count is not over $1500000 / \mathrm{mm}^{3}$ ), while anticoagulant prophylaxis of venous thrombosis is recommended in those found in high-risk situations or after the first event ${ }^{7}$.

Unfortunately, the traditional tests used in order to explore the coagulation do not accurately reflect the balance between pro- and anti-coagulant factors, nor the effects of platelet or other blood cells ${ }^{11}$. A feasible solution could be the study of thrombin generation with calibrated automated thrombography, as thrombin generation reflects more correctly the balance between pro- and anticoagulant factors.

\section{THE RELATIONSHIP BETWEEN THROMBIN GENERATION AND PLATELETS}

Adenosine diphosphate (ADP)-induced thrombin generation was significantly higher in polycythemia vera and essential thrombocythemia patients compared to control group. Those who were JAK2 V617F-positive had the highest values. It was observed that annexin $\mathrm{V}$ was less able to inhibit both basal and ADP-induced thrombin generation $^{8}$. Indeed, the hypercoagulability of $\mathrm{Ph}$-negative MPN patients is platelet-dependent. The thrombin generation potential of platelet-rich plasma and isolated platelets was significantly higher than that of healthy subjects and was associated with platelet activation. The highest levels of thrombin generation potential and tissue factor and P-selectin found on the platelet surface were present in JAK2 V617F-positive patients. JAK2 V617F allele burden increase correlated with a higher thrombin generation potential in patients who were not treated with hydroxycarbamidum. This drug was able to decrease platelet thrombin generation potential compared to the patients who did not receive this medication and led to the lower values in $J A K 2 \mathrm{~V} 617 \mathrm{~F}$-positive patients treated with it $^{12}$.
But cancer patients have high levels of circulating tissue factor, which is involved in thrombin generation - the most powerful platelet activator ${ }^{13}$.

The mechanisms involved in the platelet energy production of essential thrombocythemia patients have an initial hyperactivity induced by adding thrombin in vitro: a higher quantity of lactate was generated by platelets at 5 minutes ${ }^{14}$. This can explain the platelet activation induced by thrombin generation in these patients. In addition, increased platelet activation is explained knowing that the generation of thrombin is also increased in essential thrombocythemia patients.

In a study on 111 patients with Ph-negative MPN and 89 control subjects the endogenous thrombin potential (ETP) was higher in the patients. There was a direct correlation between ETP and platelet counts and an inverse one between ETP and antithrombin, protein C, and free protein $\mathrm{S}$ levels ${ }^{11}$. ETP ratios were lower in patients treated with hydroxycarbamidum versus those treated with other drugs. In this study, thrombin generation was able to detect a procoagulant imbalance in patients with $\mathrm{Ph}$-negative MPN $^{11}$.

\section{ACQUIRED RESISTANCE TO ACTIVATED PROTEIN C}

Not only do clonal blood cells of patients with $\mathrm{Ph}$ negative MPN manifest prothrombotic features, but vascular cells also have abnormalities and acquire a procoagulant role when they are exposed to inflammatory stimuli. The acquired resistance to activated protein $\mathrm{C}$ is involved in thrombin generation increase. This high level of thrombin generation and that of procoagulant microparticles released from platelets and vascular cells contribute to the prothrombotic feature of these patients 9 .

Compared to controls, endogenous thrombin potential was lower in the absence and higher in the presence of activated protein $\mathrm{C}$ in essential thrombocythemia and polycythemia vera patients, a fact explained by the presence of acquired activated protein $\mathrm{C}$ resistance, probably due to a reduction in plasma free protein $\mathrm{S}$ levels. Normalized activated protein $\mathrm{C}$ sensitivity ratio, which expresses the level of activated protein $\mathrm{C}$ resistance, had the highest values in $J A K 2$ V617F-positive homozygous patients ${ }^{15}$. Essential thrombocythemia and polycythemia vera patients, in particular those who are $J A K 2$ V617Fpositive, also had reduced levels of prothrombin, factor $\mathrm{V}$, and tissue factor pathway inhibitor ${ }^{15}$.

\section{THE ROLE OF MICROPARTICLES IN HYPERCOAGULABILITY}

Soluble tissue factor and microparticles are thrombotic risk factors in cancer patients ${ }^{16}$ and microparticles are also known to be biomarkers of a prothrombotic state ${ }^{17}$. Their activity can be assessed by circulating procoagulant activity (CPA). It was found that patients with Ph-negative 
MPN have a higher CPA compared to healthy subjects. This increased PCA was associated with a lower inhibition of the thrombin generation in the presence of thrombomodulin, which suggests an acquired thrombomodulin resistance in patients with Ph-negative MPN, partly due to circulating microparticles, a pathophysiological component of their hypercoagulable state ${ }^{17}$. Thrombomodulin is a thrombin cofactor in the process of protein $\mathrm{C}$ activation (a powerful anticoagulant factor), but the complex thrombinthrombomodulin is also involved in fibrinolysis inhibition. The lowest inhibition rate of the thrombin generation was observed in homozygous $J A K 2$ V617F-positive patients ${ }^{17}$.

The number of microparticles with platelet and endothelial origin (positive for CD41, and respectively CD62E and CD144 antigens) found in the serum of patients with essential thrombocythemia was higher than in the control group and suggests a double cell activation (platelet and endothelial). The presence of microparticles which simultaneously express CD62E and CD41 was only discovered in patients with thrombotic risk factors and suggests a possible bilineage source ${ }^{18}$. There was a correlation between the higher peak height of thrombin generation found in these patients and total number of microparticles, a fact that highlights the role of microparticles in thrombin generation and thrombosis ${ }^{18}$.

The platelet-free plasma of patients with essential thrombocythemia had higher thrombin generation and procoagulant phospholipid activities compared to the control group. These two activities were associated with more elevated levels of FVIIa/antithrombin complex and microparticle-associated tissue factor antigen. JAK2 V617Fpositive patients had higher thrombin generation versus $J A K 2$ V617F-negative and normal subjects. Different parameters for thrombin generation were correlated with procoagulant phospholipid-assay. No differences were found concerning thrombin generation or procoagulant activity between patients with and without thrombosis ${ }^{19}$.

\section{THE DIFFERENTIAL DIAGNOSIS BETWEEN REACTIVE THROMBOCYTOSIS AND ESSENTIAL THROMBOCYTHEMIA}

Procoagulant phospholipids-assay and the use of calibrated automated thrombogram can contribute to the differential diagnosis between reactive thrombocytosis and essential thrombocythemia. Essential thrombocythemia patients had higher levels of circulating procoagulant phospholipids compared to those with reactive thrombocytosis. Instead, those with reactive thrombocytosis had a longer lag time and more increased levels of endogenous thrombin potential, velocity index, and peak of thrombin generation $^{20}$.

\section{CONCLUSION}

The study of thrombin generation could be more useful for predicting the thrombotic risk in patients with thrombocytosis than the classical tests used for coagulation investigation.

Extensive studies are needed on patients with $\mathrm{Ph}$ negative MPN in order to establish if the level of thrombin generation correlates with thrombotic risk, and if this risk is not dependent on $J A K 2 \mathrm{~V} 617 \mathrm{~F}$ allele burden, as this mutation can influence leukocyte count, platelet and white blood cell activation ${ }^{21}$ and interaction and some factors involved in plasma hypercoagulation ${ }^{22}$.

Some thrombin generation parameters could be added to the thrombotic risk scores used in Ph-negative MPN patients, beside patient- and disease-related factors.

The association of high level of thrombin generation parameters with a high mean platelet volume, which is a recognized independent risk factor for stroke in patients with atrial fibrillation ${ }^{23}$, or with the presence of microparticles which simultaneously express CD62E and CD41 in Ph-negative MPN patients could be other aims for future thrombotic risk studies.

\section{Search strategy and selection criteria}

Strategy research aimed at analysing the utility of thrombin generation as biomarker for thrombotic risk estimation. Scientific articles published in PubMed from 2007 to 2016 were searched, using the terms "thrombin generation", "essential thrombocythemia", "polycythemia vera".

\section{ABBREVIATIONS}

ADP, adenosine diphosphate; Ph-negative MPN, Philadelphia-negative myeloproliferative neoplasms; ETP, endogenous thrombin potential; CPA, circulating procoagulant activity.

Conflict of interest statement: The author states that there are no conflicts of interest regarding the publication of this article.

\section{REFERENCES}

1. Khorana AA, Kuderer NM, Culakova E, Lyman GH, Francis CW. Development and validation of a predictive model for chemotherapy-associated thrombosis. Blood 2008;111:4902-7.

2. Khorana AA, Francis CW, Culakova E, Kuderer NM, Lyman GH. Frequency, risk factors, and trends for venous thromboembolism among hospitalized cancer patients. Cancer 2007;110(10):2339-46.

3. Passamonti F, Rumi E, Pungolino E, Malabarba L, Bertazzoni $P$, Valentini M, Orlandi E, Arcaini L, Brusamolino E, Pascutto C, Cazzola M, Morra E, Lazzarino M. Life expectancy and prognostic factors for survival in patients with polycythemia vera and essential thrombocythemia. Am J Med 2004;117:755-61.

4. Barbui T, Finazzi G, Carobbio A, Thiele J, Passamonti F, Rumi E, Ruggeri M, Rodeghiero F, Randi ML, Bertozzi I, Gisslinger H, BuxhoferAusch V, De Stefano V, Betti S, Rambaldi A, Vannucchi AM, Tefferi A. Development and validation of an International Prognostic Score of thrombosis in WHO-Essential Thrombocythemia (IPSET-thrombosis). Blood 2012;120(26):5128-33. doi: 10.1182/blood-2012-07-444067.

5. Barbui T, Barosi G, Birgegard G, Cervantes F, Finazzi G, Griesshammer M, Harrison C, Hasselbalch HC, Hehlmann R, Hoffman R, Kiladjian JJ, Kröger N, Mesa R, McMullin MF, Pardanani A, Passamonti F, Vannucchi AM, Reiter A, Silver RT, Verstovsek S, Tefferi A; European 
LeukemiaNet. Philadelphia-negative classical myeloproliferative neoplasms: critical concepts and management recommendations from European LeukemiaNet. J Clin Oncol 2011;29:761-70.

6. Tevet M, lonescu R, Dragan C, Lupu AR. Influence of the JAK2 V617F mutation and inherited thrombophilia on the thrombotic risk among patients with myeloproliferative disorders. Maedica (Bucharest) 2015;10(1):27-32.

7. Artoni A, Bucciarelli P, Martinelli I. Cerebral thrombosis and myeloproliferative neoplasms. Curr Neurol Neurosci Rep 2014;14(11):496.

8. Panova-Noeva M, Marchetti M, Russo L, Tartari CJ, Leuzzi A Finazzi G, Rambaldi A, ten Cate H, Falanga A. ADP-induced platelet aggregation and thrombin generation are increased in Essential Thrombocythemia and Polycythemia Vera. Thromb Res 2013;132(1):88-93

9. Falanga A, Marchetti M. Thrombotic disease in the myeloproliferative neoplasms. Hematology Am Soc Hematol Educ Program 2012;2012:571-81.

10. Perrin J, Ranta D, Empereur F, Vigneron C, Feugier P, Lecompte T. Polymorphonuclear neutrophils from JAK2(V617F) positive MPD patients do not support hypercoagulability: A study with calibrated automated thrombography (CAT). Blood Cells Mol Dis 2011;46(3):235-8.

11. Tripodi A, Chantarangkul V, Gianniello F, Clerici M, Lemma L, Padovan L, Gatti L, Mannucci PM, Peyvandi F. Global coagulation in myeloproliferative neoplasms. Ann Hematol 2013;92(12):1633-9.

12. Panova-Noeva M, Marchetti M, Spronk HM, Russo L, Diani E, Finazz G, Salmoiraghi S, Rambaldi A, Barbui T, Ten Cate H, Falanga A Platelet-induced thrombin generation by the calibrated automated thrombogram assay is increased in patients with essential thrombocythemia and polycythemia vera. Am J Hematol 2011;86(4):337-42.

13. van Es N, Sturk A, Middeldorp S, Nieuwland R. Effects of cancer on platelets. Semin Oncol 2014;41(3):311-8.

14. Trappenburg MC, van Schilfgaarde M, Marchetti M, Spronk HM, ten Cate $\mathrm{H}$, Leyte A, Terpstra WE, Falanga A. Elevated procoagulant microparticles expressing endothelial and platelet markers in essential thrombocythemia. Haematologica 2009;94(7):911-8.
15. Marchetti M, Castoldi E, Spronk HM, van Oerle R, Balducci D, Barbui T, Rosing J, Ten Cate H, Falanga A. Thrombin generation and activated protein $C$ resistance in patients with essential thrombocythemia and polycythemia vera. Blood 2008;112(10):4061-8

16. Mege D, Mezouar S, Dignat-George F, Panicot-Dubois L, Dubois C Microparticles and cancer thrombosis in animal models. Thromb Res 2016;140 Suppl 1:S21-6.

17. Duchemin J, Ugo V, lanotto JC, Lecucq L, Mercier B, Abgrall JF. Increased circulating procoagulant activity and thrombin generation in patients with myeloproliferative neoplasms. Thromb Res 2010;126(3):238-42.

18. Cesar JM, Pallares E, Rubí J, Navarro JL. Lactate production by thrombin-activated platelets of patients with primary thrombocythemia. Thromb Res 2006;118(3):335-9.

19. Marchetti M, Tartari CJ, Russo L, Panova-Noeva M, Leuzzi A, Rambaldi A, Finazzi G, Woodhams B, Falanga A. Phospholipid-dependent procoagulant activity is highly expressed by circulating microparticles in patients with essential thrombocythemia. Am J Hematol 2014;89(1):68-73.

20. Mignon I, Grand F, Boyer F, Hunault-Berger M, Hamel JF, Macchi L. Thrombin generation and procoagulant phospholipids in patients with essential thrombocythemia and reactive thrombocytosis. Am J Hematol 2013:88(12):1007-11.

21. Passamonti F, Rumi E, Pietra D, Della Porta MG, Boveri E, Pascutto C Vanelli L, Arcaini L, Burcheri S, Malcovati L, Lazzarino M, Cazzola M. Relation between JAK2 (V617F) mutation status, granulocyte activation, and constitutive mobilization of CD34+ cells into peripheral blood in myeloproliferative disorders. Blood 2006;107:3676-82.

22. Falanga A, Marchetti M, Vignoli A, Balducci D, Russo L, Guerini V Barbui T. V617F JAK-2 mutation in patients with essential thrombocythemia: relation to platelet, granulocyte, and plasma hemostatic and inflammatory molecules. Exp Hematol 2007;35:702-11.

23. Turfan M, Erdogan E, Ertas G, Duran M, Murat SN, Celik E, Baydar C, Tasal A, Vatankulu MA, Sevgili E, Kul S, Yoldas T, Goktekin O. Usefulness of mean platelet volume for predicting stroke risk in atrial fibrillation patients. Blood Coagul Fibrinolysis 2013;24(1):55-8. 